\title{
Acetaminophen-induced hepato- and nephrotoxicity and amelioration by hydroalcoholic polyherbal formulation in experimental rodents
}

\author{
Anuj Kumar Srivastava', D. Kaushik², V. K. Lal ${ }^{3}$
}

${ }^{1}$ Department of Pharmacognosy, Anand College Pharmacy, Agra, Uttar Pradesh, India, ${ }^{2}$ Department of
Pharmaceutical Chemistry, Agra Public Pharmacy College, Agra, Uttar Pradesh, India, ${ }^{3}$ Department of
Pharmacognosy, Central Council for Research in Ayurvedic Sciences, Ministry of AYUSH, New Delhi, India

Abstract

Objective: The objective of this study was to evaluate hepato- and nephroprotective potential of extracts of polyherbal formulations against acetaminophen (paracetamol [PCM])-induced dysfunction in experimental rodents. Materials and Methods: Acute and subacute toxicity study of hydroalcoholic polyherbal formulation (HAF) was performed according to the OECD guidelines. Sprague Dawley female rats were grouped into three containing six animals each for acute toxicity study. For subacute toxicity study, animals were observed periodically for the symptoms of toxicity and death within $24 \mathrm{~h}$ and then daily for 14 days. Acetaminophen-induced hepato- and nephrotoxicity models were used for this study. Hepatotoxicity and nephrotoxicity were performed it to control group rats received normal saline (p.o.) per day for 7 days. Hepatotoxicity and nephrotoxicity induced by acetaminophen (PCM) were administered at a dose of $750 \mathrm{mg} / \mathrm{kg} /$ day/oral for 7 day and Groups III \& IV were treated with PCM $(750 \mathrm{mg} / \mathrm{kg} /$ day/oral) and HAF of doses 200 and $400 \mathrm{mg} / \mathrm{kg} /$ day/oral for 7 days respectively. The liver weight, kidney weight, liver function test, and kidney function test were evaluated along with histopathological investigation in various experimental groups of rats. Results: It was observed that the PCM treatment induced significant elevation $(P<$ 0.001 ) in creatinine, kidney weight, liver weight, and liver functions such as alanine aminotransferase (ALT), aspartate aminotransferase (AST), and triglycerides. Treatment of HAF of doses 200 and $400 \mathrm{mg} / \mathrm{kg} / \mathrm{d}$ (p.o) for 7 day) on experimental rats recorded significant decrement (up to $P<0.001$ ) in creatinine, kidney weight, liver weight, and liver functions such as ALT and AST. The doses of $400 \mathrm{mg} / \mathrm{kg} / \mathrm{body}$ weight/oral of HAF were found significant when compare with at doses of $200 \mathrm{mg} / \mathrm{kg} /$ body weight/oral. A histological observation of liver and kidney tissues provides positive response on experimental groups having PCM + HAF $400 \mathrm{mg} / \mathrm{kg}$-induced model and significant data also correlate the biochemical parameters. Conclusions: This finding powerfully supports that polyherbal formulation acts in the liver and kidney as a potent scavenger of free radicals to prevent the toxic effects of PCM. The biochemical and histopathological parameters of polyherbal formulation validate its ethnomedicinal uses and polyphenolic presence.

Key words: Biochemical, histopathology, nephrotoxicity

\section{INTRODUCTION}

$\mathrm{P}$ aracetamol (PCM) (acetaminophen) is one of the most commonly used analgesic-antipyretic drugs worldwide, and in most countries, it is available without a prescription ${ }^{[1]} \mathrm{PCM}$ overdose is known to cause hepatotoxicity and numerous studies about PCM -induced hepatotoxicity, and its mechanisms are available in the literature. ${ }^{[2-4]}$ Significant PCM -induced hepatotoxicity usually triggers nephrotoxicity ${ }^{[5]}$ Renal insufficiency is reported to occur in $1-2 \%$ of patients exposed to PCM. ${ }^{[6]}$ After oral administration, about $63 \%$ of PCM is metabolized through glucuronidation and 34\% through sulfation primarily in the liver. The water-soluble metabolites consisting of these metabolic pathways are excreted through the kidney. $\mathrm{N}$-acetyl-p-benzoquinone is a reactive intermediate that occurs

\section{Address for correspondence:}

Anuj Kumar Srivastava, Anand College Pharmacy, Agra - 282 007, Uttar Pradesh, India. Tel.: +91-7465057756.

E-mail: anuj_pharmacognosy@rediffmail.com

Received: $19-04-2018$

Revised: 02-10-2018

Accepted: 26-10-2018 
Table 1: Composition of polyherbal formulation

\begin{tabular}{llll} 
Name of drug & Authentication number & Part used & Quantity (in parts) \\
\hline Formulation (HAF) & & & \\
\hline Bergenia ciliata & NISCAIR/RHMD/CONSULT/2016/2976-03-5 & Roots & 2 part \\
Pedalium murex & NISCAIR/RHMD/CONSULT/2016/2976-03-1 & Fruits & 2 part \\
Tribulus terrestris & NISCAIR/RHMD/CONSULT/2017/3050-77-6 & Fruits & 2 part \\
Sphaeranthus indicus & NISCAIR/RHMD/CONSULT/2016/2976-03-4 & Flowers & 2 part \\
Tinospora cordifolia & NISCAIR/RHMD/CONSULT/2016/2976-03-2 & Stem & 2 part \\
Piper longum & NISCAIR/RHMD/CONSULT/2016/2976-03-3 & Fruits & 1 part \\
\hline
\end{tabular}

HAF: Hydroalcoholic polyherbal formulation

Table 2: Acute toxicity study of polyherbal formulation (HAF)

\begin{tabular}{llll} 
Acute toxicity study sign & HAF & & \\
\cline { 2 - 4 } & F $\mathbf{1}(\mathbf{3 0 0} \mathbf{~ m g} / \mathbf{k g})$ b.w. $(\boldsymbol{n}=\mathbf{1})$ & $\mathbf{F} \mathbf{2}(\mathbf{2 0 0 0} \mathbf{~ m g} / \mathbf{k g}$ b.w. $(\boldsymbol{n}=\mathbf{1})$ & F3 (2000 $\mathbf{~ g g / k g ~ b . w . ~}(\boldsymbol{n}=\mathbf{4})$ \\
\hline Lacrimation & No & No & No \\
Salivation & No & No & No \\
Piloerection & No & No & No \\
Drowsiness & No & No & No \\
Tremors & No & No & No \\
Convulsion & No & No & No \\
Skin & Normal & Normal & Normal \\
Body weight (g) & 120 & 118 & 117 \\
Food consumption & Normal & Normal & Normal \\
Water consumption & Normal & Normal & Normal \\
Mortality & No & No & No \\
\hline
\end{tabular}

F: Female rat (Sprague Dawley rat), HAF: Hydroalcoholic polyherbal formulation

when oxidization of $<5 \%$ of PCM takes place by the microsomal P-450 enzyme system. ${ }^{[7]}$ Acute toxicity of acetaminophen in the liver is mediated by cytochrome P450 mixed function oxidase and toxicity is enhanced by compounds which induce the enzyme. Acute renal cortical toxicity is mediated by two or three enzyme systems: Cytochrome-P450 m.f.o., prostaglandin endoperoxide synthetase, and possibly deacetylase ${ }^{[8,9]}$ Chronic toxicity manifested by analgesic nephropathy with renal inner medullary necrosis is mediated by prostaglandin endoperoxide synthetase, and toxicity is enhanced by salicylates. The present study sought to investigate the hepato- and nephroprotective capacity of polyherbal formulation (hydroalcoholic polyherbal formulation [HAF]) which is combination of Bergenia ciliata, Pedalium murex, Tribulus terrestris, Tinospora cordifolia, Sphaeranthus indicus, and Piper longum. ${ }^{[10,11]}$

\section{MATERIALS AND METHODS}

\section{Collection, Preparation and Extraction of Herbal Samples}

All the medicinal plant materials were collected from different geographical areas of districts Fatehpur, Deoria, and Agra, Uttar Pradesh, India. All the medicinal plants were authenticated from the National Institute of Science Communication and Information Research, New Delhi, India, under the supervision of scientist Dr. Sunita Garg with different authentication numbers [Table 1].

\section{Plant Extraction}

Selected parts of the plants were used for extraction and then dried for 2 weeks under shade at room temperature, subjected to size reduction with a crusher and then passed through sieve no. 40 to get uniform powder. ${ }^{[12,13]}$ Around $250 \mathrm{~g}$ of individual powdered plant material was subjected to extraction with solvent such as petroleum ether (for the purpose of defatting) and alcohol (60\%). The hydro-alcoholic (40:60) extracts were subjected for maceration process of cold extraction. Each extract was then distilled to dryness under reduced pressure using rotatory evaporator to yield the respective dried extracts.

\section{Herbal Formulations}

The amount of composition of powder extracts contained the ethanolic $(60 \%)$ extracts was used for the preparation of polyherbal formulation as mentioned in Table 1. The standardization of the polyherbal formulation was tested as 


\begin{tabular}{|c|c|c|c|c|c|c|}
\hline Treatment & Dose (mg/kg) b.w. & Dose volume (ml) & Number of animals & Sex & Clinical sign & Mortality \\
\hline Sighting study step-I & 300 & 1 & 01 & $\mathrm{~F}$ & $\mathrm{~N}$ & 0 out 1 \\
\hline Sighting study step-II & 2000 & 1 & 01 & $\mathrm{~F}$ & $\mathrm{~N}$ & 0 out 1 \\
\hline Main study & 2000 & 1 & 04 & $\mathrm{~F}$ & $\mathrm{~N}$ & 0 out 4 \\
\hline
\end{tabular}

N: Normal, F: Female

Table 4: Hematological and biochemical parameters of animals during subacute toxicity study

\begin{tabular}{|c|c|c|}
\hline \multirow[t]{2}{*}{ Parameters } & \multirow[t]{2}{*}{$\begin{array}{l}\text { Clinical } \\
\text { parameters }\end{array}$} & $\begin{array}{c}\text { Extracts values of } \\
\text { polyherbal formulation }\end{array}$ \\
\hline & & $\begin{array}{c}\text { HAF (200 mg/kg) body } \\
\text { weight }\end{array}$ \\
\hline \multirow[t]{2}{*}{ Body weight } & Pre-treatment & $158 \pm 6.44$ \\
\hline & Post-treatment & $162 \pm 5.91$ \\
\hline \multirow[t]{2}{*}{$\mathrm{HB}(\mathrm{g} \%)$} & Pre-treatment & $12.80 \pm 0.92$ \\
\hline & Post-treatment & $12.30 \pm 0.85$ \\
\hline \multirow[t]{2}{*}{ RBC count } & Pre-treatment & $6.40 \pm 0.30$ \\
\hline & Post-treatment & $6.40 \pm 0.17$ \\
\hline \multirow[t]{2}{*}{ WBC count } & Pre-treatment & $9.30 \pm 0.6$ \\
\hline & Post-treatment & $8.90 \pm 0.27$ \\
\hline \multirow[t]{2}{*}{ Urea } & Pre-treatment & $29.50 \pm 1.71$ \\
\hline & Post-treatment & $34.00 \pm 1.27$ \\
\hline \multirow[t]{2}{*}{ Creatinine } & Pre-treatment & $0.80 \pm 0.10$ \\
\hline & Post-treatment & $0.90 \pm 0.02$ \\
\hline \multirow[t]{2}{*}{ SGOT } & Pre-treatment & $41.10 \pm 2.64$ \\
\hline & Post-treatment & $42.80 \pm 2.90$ \\
\hline \multirow[t]{2}{*}{ SGPT } & Pre-treatment & $40.50 \pm 3.05$ \\
\hline & Post-treatment & $45.30 \pm 2.95$ \\
\hline \multirow[t]{2}{*}{ Blood sugar } & Pre-treatment & $94.50 \pm 2.72$ \\
\hline & Post-treatment & $90.50 \pm 1.89$ \\
\hline
\end{tabular}

Statistical data expressed in mean \pm SEM $(n=6)$. SEM: Standard error of the mean, HAF: Hydroalcoholic polyherbal formulation, HB: Hemoglobin, RBC: Red blood cell, WBC: White blood cell, SGOT: Serum glutamic oxaloacetic transaminase, SGPT: Serum glutamic pyruvic transaminase

per the WHO guidelines for the quality control of herbal materials. $^{[14-16]}$

\section{Animal Ethical Committee Approval}

The study was performed after permission of the Institutional Animal Ethical Committee (IAEC) of Anand College of Pharmacy, Agra, Uttar Pradesh, India (CPCSEA/IAEC/ ACP/2017/15). All animals were housed in facilities approved by international guidelines.

\section{Acute and Subacute Oral Toxicity Studies}

Acute toxicity study was performed according to the OECD guidelines No.420. Sprague Dawley female rats were grouped in to three containing six animals. Animals were observed periodically for the symptoms of toxicity and death within $24 \mathrm{~h}$ and then daily for 14 days. HAF was administered orally at a single dose level of $300 \mathrm{mg} / \mathrm{kg} / \mathrm{b}$.w to one animal for sighting study step-I. In Sighting study step-II, HAF was administered orally at a single dose level of $2000 \mathrm{mg} / \mathrm{kg} / \mathrm{body}$ weight/oral to single animal, The altered autonomic effects (lacrimation, salivation, piloerection) central nervous system effect (tremors, convulsion, drowsiness) skin, body weight, food consumption, water consumption and mortality [Table 3] were observed. For the final study, HAF was administered at a dose of $2000 \mathrm{mg} / \mathrm{kg} /$ body weight to group of four animals. The summary of clinical sign and mortality of HAF is shown in Table 3. The maximum dose tested $(2000 \mathrm{mg} / \mathrm{kg})$ for $\mathrm{LD}_{50}$. From the $\mathrm{LD}_{50}$, doses such as $1 / 5^{\text {th }}$ and $1 / 10^{\text {th }}$ were selected and considered for further study, i.e., 200 and $400 \mathrm{mg} / \mathrm{kg}$ body weight. The subacute toxicity studies of the formulations were determined as per the OECD guidelines. Sprague Dawley female rats were grouped for daily oral administration of HAF at individual doses of 200 and $400 \mathrm{mg} / \mathrm{kg} / \mathrm{b}$.w for 28 consecutive days. ${ }^{[17,18]}$ The haematological and biochemical parameters were found significant [Table 4] during sub-acute toxicity studies.

\section{Experimental Design}

The Wister albino rats of 9-12 weeks old weighing about 150-200 g were randomly divided into the following four groups, with each group containing five rats. The animals were maintained under standard environmental condition $\left(23-25^{\circ} \mathrm{C}, 12 \mathrm{~h} / 12 \mathrm{~h}\right.$ light/dark cycle) and had free access to standard pellet diet, water ad libitum. The animals were acclimatized to the laboratory environment for a week before the of the start study. ${ }^{[19,20]}$ Group (I) treated as control, Group (II) treated as (experimental Group) liver and kidney toxicities indced by PCM $(750 \mathrm{mg} / \mathrm{kg}$ body weight/oral, Group (III) treated as combination doses of PCM $(750 \mathrm{mg} /$ $\mathrm{kg} /$ body weight/oral $)+\mathrm{HAF}$ (200 mg/kg/body weight/ oral), Group (VI) Treated as combination doses of PCM (750 $\mathrm{mg} / \mathrm{kg} /$ body weight/oral) + HAF (400 mg/kg/body weight/ oral). [Tables 5 and 6]. The groups were housed separately in different cages for 7 days..$^{[21-25]}$

\section{Biochemical Studies}

After collection of blood, animals were sacrificed by cervical dislocation under mild ether anesthesia, and liver and kidneys 
Table 5: Effect of HAF on liver function of paracetamol-induced liver injury rat model

\begin{tabular}{lcccccc} 
Groups & Liver weight $(\mathbf{g})$ & Total bilirubin $(\mathbf{m g} \%)$ & AST (IU/L) & ALT (IU/L) & ALP (IU/L) & Cholesterol (mg/dl) \\
\hline NC & $6.35 \pm 0.13$ & $0.52 \pm 0.10$ & $95.4 \pm 2.50$ & $154.5 \pm 2.30$ & $122.67 \pm 9.95$ & $45.02 \pm 2.1$ \\
TC & $8.0 \pm 0.17$ & $1.05 \pm 0.50$ & $205 \pm 1.02$ & $283.96 \pm 3.20$ & $290 \pm 2.00$ & $74.50 \pm 0.52$ \\
HAF-I $(200 \mathrm{mg} / \mathrm{kg})$ & $7.48 \pm 1.25^{\mathrm{a}}$ & $0.82 \pm 0.04^{\mathrm{a}}$ & $157 \pm 0.24^{\mathrm{b}}$ & $210.20 \pm 1.25^{\mathrm{b}}$ & $180.1 \pm 0.25^{\mathrm{a}}$ & $67.45 \pm 3.25^{\mathrm{b}}$ \\
HAF-I $(400 \mathrm{mg} / \mathrm{kg})$ & $6.42 \pm 0.24^{\mathrm{a}}$ & $0.60 \pm 0.15^{\mathrm{a}}$ & $120 \pm 1.50^{\mathrm{a}}$ & $168.26 \pm 2.25^{\mathrm{a}}$ & $135.5 \pm 0.70^{\mathrm{b}}$ & $52.25 \pm 2.20^{\mathrm{b}}$ \\
\hline
\end{tabular}

NC: Normal control, TC: Toxic control, AST: Aspartate aminotransferase, ALT: Alanine aminotransferase, ALP: Alkaline phosphatase. In this data, each group contain six animals. The Neuman Kaul's test was performed between control versus PCM-induced group and PCM versus respective polyherbal-treated groups. Where a is highly significant $(P<0.0001), \mathrm{b}$ is significant $(P<0.001)$, and Ns is non-significant $(P>0.05)$. PCM: Paracetamol, HAF: Hydroalcoholic polyherbal formulation

Table 6: Effect of polyherbal formulation (HAF) on renal function test

\begin{tabular}{lcccrr} 
Groups & B.W $(\mathbf{g})$ & K.W. $(\mathbf{g})$ & SU $(\mathbf{m g} / \mathbf{m l})$ & SC $(\mathbf{m g} / \mathbf{m l})$ & BUN $(\mathbf{m g} / \mathbf{l})$ \\
\hline NC & $171 \pm 1.18$ & $1.6 \pm 0.03$ & $37.21 \pm 0.99$ & $1.71 \pm 0.72$ & $18.43 \pm 0.65$ \\
TC & $153.8 \pm 1.74$ & $2.4 \pm 1.02$ & $99.12 \pm 1.05$ & $3.11 \pm 0.75$ & $45.20 \pm 0.50$ \\
HAF-I $(200 \mathrm{mg} / \mathrm{kg})$ & $171.6 \pm 1.435^{\mathrm{a}}$ & $1.65 \pm 0.20^{\mathrm{a}}$ & $58.45 \pm 1.05^{\mathrm{b}}$ & $2.10 \pm 0.62^{\mathrm{a}}$ & $26.90 \pm 0.95^{\mathrm{a}}$ \\
HAF-I $(400 \mathrm{mg} / \mathrm{kg})$ & $168.6 \pm 0.979^{\mathrm{a}}$ & $1.32 \pm 1.25^{\mathrm{b}}$ & $43.32 \pm 0.38^{\mathrm{b}}$ & $1.75 \pm 0.25^{\mathrm{b}}$ & $20.4 \pm 1.20^{\mathrm{a}}$ \\
\hline
\end{tabular}

BW: Body weight, KW: Kidney weight, SU: Serum urea, SC: Serum creatinine, BUN: Blood urea nitrogen. In this data, each group contain six animals. The Neuman Kaul's test was performed between control versus PCM-induced group and PCM Versus respective poly herbal treated groups. Where a is highly significant $(P<0.0001)$, b is significant $(P<0.001)$, And Ns is non-significant $(P>0.05)$. HAF: Hydro-alcoholic polyherbal formulation, PCM: Paracetamol

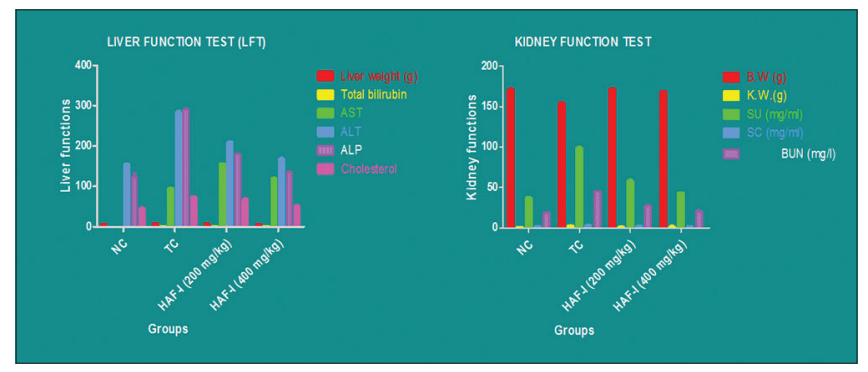

Figure 1: In this data, each group contain six animals. The Neuman Kaul's test was performed between control versus paracetamol (PCM)-induced group and PCM versus respective polyherbaltreated groups. Where a is highly significant $(P<0.0001)$, b is significant $(P<0.001)$, and Ns is non-significant $(P>0.05)$. BW - Body weight, KW - Kidney weight, SU - Serum urea, SC - Serum creatinine, BUN - Blood urea nitrogen

were harvested, rinsed in saline, and stored at $-80^{\circ} \mathrm{C}$ until further biochemical analysis ${ }^{[26]}$ Liver function tests and renal function tests were measured to observe the oxidative stress level in serum. ${ }^{[27-32]}$

\section{Histological Analysis}

\section{Histopathological studies of the liver}

Liver tissues were cut in small pieces and immersed in neutral buffered formalin for $24 \mathrm{~h}$. The fixed tissues were processed routinely, embedded in paraffin, sectioned, deparaffinized, and rehydrated using the standard techniques. The extent of PCM -induced necrosis was evaluated by assessing the morphological changes in the liver sections stained with hematoxylin and eosin ( $\mathrm{H}$ and $\mathrm{E})$, using standard techniques
[Figure 1].

\section{Histopathological studies of the kidney}

Pieces of the kidney from each group were fixed immediately in $10 \%$ neutral formalin for a period of at least $24 \mathrm{~h}$, dehydrated in graded (50-100\%) alcohol, embedded in paraffin wax, cut into 4-5 $\mu \mathrm{m}$ thick sections, and stained with $\mathrm{H}$ and $\mathrm{E}$. The sections were evaluated for the pathological symptoms of nephrotoxicity such as necrosis, fatty infiltration, fibrosis, lymphocyte infiltration, and blood vessel congestion [Figure 2].

\section{RESULTS AND DISCUSSION}

\section{Acute and Subacute Toxicity Studies}

No abnormality and sign of toxicity produced at a dose of $2000 \mathrm{mg} / \mathrm{kg}$ body weight. The HAF was found to be safe up to a dose of $2000 \mathrm{mg} / \mathrm{kg}$ body weight and the data are shown in Tables 2 and 3. The doses of $200 \mathrm{mg} / \mathrm{kg}$ and $400 \mathrm{mg} / \mathrm{kg}$ body weight were selected for formulation based on the results of acute and subacute toxicity study.

\section{Experimental Design}

\section{Quantification of liver tests}

There were no significant changes in bilirubin values among all the experimental groups studied. Aspartate amino-transferase, alanine aminotransferase, and alkaline phosphatase levels increased in toxic control group while treatment resulted in decreasing these values and the 


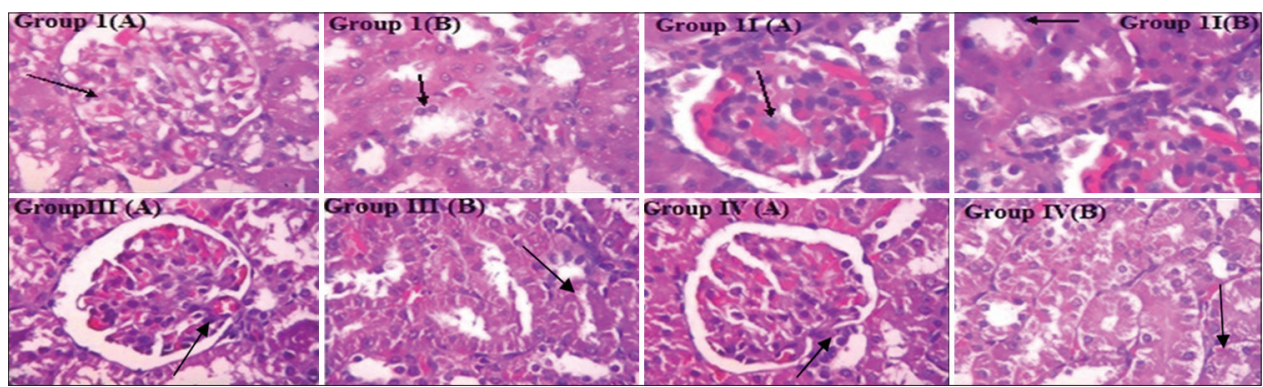

Figure 2: Histopathology of negative and positive control group in glomerulus and renal tubules. Group I negative control showed intact architecture of renal parenchyma. In glomerulus [Group IA, Arrow], Bowman's space and mesangial cells appeared intact. In intact renal tubules [Group IB, Arrow], blood vessels and interstitium were unremarkable. Group II: Positive control, i.e., PCM treated showed focally distorted renal parenchyma architecture [mainly tubules]. In glomerulus [Group IIA, Arrow]: Intact Bowman's space, extravasation of erythrocytes seen, Mesangial cells appear increased. Most of the renal tubules showed degenerative changes [Group IIB, Arrow]. Blood vessels and interstitium were unremarkable. Group III: Treatment done with HAF-I $200 \mathrm{mg} / \mathrm{kg}$ body weight, p.o. showed intact architecture of renal parenchyma. In glomerulus [Group IIIA, Arrow], +: Intact Bowman's space and extravasation of erythrocytes were seen; mesangial cells appear increased. Few renal tubules show degenerative changes [Group IIIB, Arrow]. Blood vessels and interstitium were unremarkable. Group IV: Treatment done with HAF-I $400 \mathrm{mg} / \mathrm{kg}$, p.o. showed intact architecture of renal parenchyma. In glomerulus [Group IVA, Arrow], extravasation of erythrocytes was seen; mesangial cells appear increased. Few renal tubules show degenerative changes [Group IVB, Arrow]. Blood vessels and interstitium were unremarkable

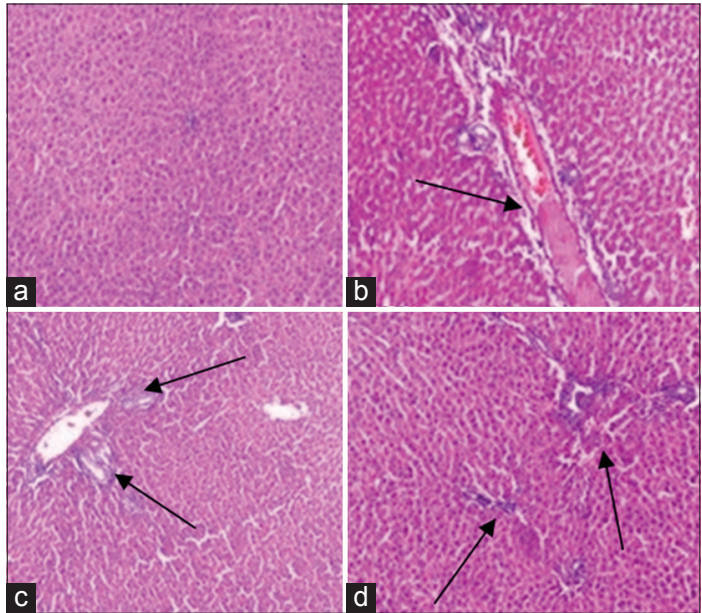

Figure 3: (a) Control group showing central vein surrounded by hepatic cord of cell, (b) paracetamol-induced liver necrosis and disruption with massive fatty changes, ballooning degeneration, and loss of cellular boundaries, (c) Group C shows mild congestion in CV, less fatty changes, and mild necrotic cells with minimal inflammatory conditions on administration of hydroalcoholic polyherbal formulation doses of $200 \mathrm{mg} / \mathrm{kg}$ p.o. for 7 days, and (d) animals shows regeneration of hepatocytes around $\mathrm{CV}$, near normal liver architecture with administration on hydroalcoholic polyherbal formulation doses of $400 \mathrm{mg} / \mathrm{kg}$ p.o. for 7 days

maximum decrease was found in HAF $400 \mathrm{mg} / \mathrm{kg}$ treated group [Table 5].

\section{Quantification of kidney test}

Table 6 shows the renal protective effect of therapy, indicating the maximum decrease in blood urea nitrogen (BUN) and serum creatinine with HAF $400 \mathrm{mg} / \mathrm{kg}$ group.
HAF $200 \mathrm{mg} / \mathrm{kg}$ group also showed a decline in BUN and creatinine levels as compared to toxic control group, but they were more than HAF $400 \mathrm{mg} / \mathrm{kg}$ dose group.

\section{Histopathological Study \\ Histopathological studies of the liver}

Histopathological study shows the protective activity of HAF. This included the histological changes in the liver architecture such as architecture of hepatic lobules, swelling of liver cells, fatty change, focal necrosis, inflammatory cell infiltration around portal area, kuffar cells, and hyperplasia. The healing effect of HAF-400 mg/kg body weight produces more significant results when compared to HAF-200 mg/kg [Figure 3].

\section{Histopathological studies of the kidney}

A histopathological study shows the curative and protective activity of HAF.

\section{CONCLUSIONS}

Overdose of PCM causes toxicity in human beings as well as in rats and produce liver and kidney damage. Thus, PCM is a suitable experimental toxin to induce hepatic and renal damage. As we gone through various studies on the treatment of kidney and renal disorders, we can conclude that herbal plants and its polyherbal formulation play a unique and important role in the liver and kidney-related medication. The phytoconstituents obtained from different plants of herbal formulation contain phenolics, tannins, flavonoids, and 
others mainly responsible for hepato- and nephroprotective activity. The aim of this research is to record experimental correlations with medicinal folk-lore for curing hepato- and nephroprotective and phytochemicals presented in the polyherbal formulation (HAF). And also, we have attempted to use our best endeavors of indigenous herbs to alternative medicine of liver and renal damage. From this study, it is clear that the HAF possesses significant hepato- and nephroprotective activity.

\section{ACKNOWLEDGMENTS}

Authors are highly obliged to Chairman Mr. P.K. Gupta, ViceChairman Mr. Y.K. Gupta, and Dean Dr. Kashmira J. Gohil, Anand College of Pharmacy, Agra (Sharda Group of Institutions), for providing laboratory support and facilities.

\section{REFERENCES}

1. Hu JJ, Yoo JS, Lin M, Wang EJ, Yang CS. Protective effects of diallyl sulfide on acetaminophen-induced toxicities. Food Chem Toxicol 1996;34:963-9.

2. Eguia L, Materson BJ. Acetaminophen-related acute renal failure without fulminant liver failure. Pharmacotherapy 1997; 17:363-70.

3. Yapar K, Kart A, Karapehlivan M, Atakisi O, Tunca R, Erginsoy S, et al. Hepatoprotective effect of L-carnitine against acute acetaminophen toxicity in mice. Exp Toxicol Pathol 2007;59:121-8.

4. Prescott L. Oral or intravenous N-acetylcysteine for acetaminophen poisoning? Ann Emerg Med 2005;45:409-13.

5. Carpenter HM, Mudge GH. Acetaminophen nephrotoxicity: Studies on renal acetylation and deacetylation. J Pharmacol Exp Ther 1981;218:161-7.

6. Singh DP, Mani D. Protective effect of triphala rasayana against paracetamol-induced hepato-renal toxicity in mice. J Ayurveda Integr Med 2015;6:181-6.

7. Dahlin DC, Miwa GT, Lu AY, Nelson SD. N-acetyl-pbenzoquinone imine: A cytochrome P-450-mediated oxidation product of acetaminophen. Proc Natl Acad Sci U S A 1984;81:1327-31.

8. Russmann S, Kullak-Ublick GA, Grattagliano I. Current concepts of mechanisms in drug-induced hepatotoxicity. Curr Med Chem 2009;16:3041-53.

9. Boyd EM, Bereczky GM. Liver necrosis from paracetamol. Br J Pharmacol Chemother 1966;26:606-14.

10. da Silva Melo DA, Saciura VC, Poloni JA, Oliveira CS, Filho JC, Padilha RZ, et al. Evaluation of renal enzymuria and cellular excretion as an marker of acute nephrotoxicity due to an overdose of paracetamol in wistar rats. Clin Chim Acta 2006;373:88-91.

11. Jodynis-Liebert J, Matławska I, Bylka W, Murias M. Protective effect of Aquilegia vulgaris (L.) on APAPinduced oxidative stress in rats. J Ethnopharmacol
2005;97:351-8.

12. Ragavan B, Monisha S. Antioxidant and phytochemical investigation of a $\mathrm{PH}$ extract. Asian J Pharm Sci 2015;3:1-11.

13. Ragavan B, Monisha S Cardioprotective potential of a hydroethanolic polyherbal crude extract on isoproterenol induced myocardial in wistar albino rats. World J Pharm Res 2016;5:1048-69.

14. Anonymous. The Ayurvedic Formulary of India. $2^{\text {nd }} e d$. New Delhi: Government of India, Ministry of Health and Family Welfare; 2003. p. 113.

15. Ananymous. Quality Control Methods for Medicinal Plant Materials. Geneva: World Health Organisation; 1998. p. 25-8.

16. Meena AK, Rao MM, Panda P. Standardization of ayurvedic polyherbal formulation, pancasama churna. Int J Pharmacog Phytochem Res 2010;1:11-4.

17. Suryavanshi SA, Kadam SK, Raina P, Nimbargi R, Pandit VA. Evaluation of acute and sub-acute toxicity of a standardized polyherbal formulation (Hc9): An in vivo study. Int J Pharm Pharm Sci 2010;7:110-7.

18. Ishtiaq S, Akram M, Kamran SH, Hanif U, Afridi MSK, Sajid-Ur-Rehman, et al. Acute and sub-acute toxicity study of a Pakistani polyherbal formulation. BMC Complement Altern Med 2017;17:387.

19. Cekmen M, Ilbey YO, Ozbek E, Simsek A, Somay A, Ersoz C, et al. Curcumin prevents oxidative renal damage induced by acetaminophen in rats. Food Chem Toxicol 2009;47:1480-4.

20. Chen TS, Richie JP, Nagasawa HT, Lang CA. Glutathione monoethyl ester protects against glutathione deficiencies due to aging and acetaminophen in mice. Mech Ageing Dev 2000;120:127-39.

21. Kheradpezhouh E, Panjehshahin MR, Miri R, Javidnia K, Noorafshan A, Monabati A, et al. Curcumin protects rats against acetaminophen-induced hepatorenal damages and shows synergistic activity with $\mathrm{N}$-acetyl cysteine. Eur J Pharmacol 2010;628:274-81.

22. Li C, Liu J, Saavedra JE, Keefer LK, Waalkes MP. The nitric oxide donor, V-PYRRO/NO, protects against acetaminophen-induced nephrotoxicity in mice. Toxicology 2003;189:173-80.

23. Palani S, Kumar RP, Kumar BS. Effect of the ethanolic extract of Indigofera barberi (L.) in acute acetaminophen induced nephrotoxic rats. N Biotech 2009;25:S14.

24. Elkomy A, Aboubakr M, Ashraf L. Ameliorative effect of thymus oil on paracetamol induced hepato-renal toxicity: A biochemical, antioxidant and histopathological studies. J Pharmacol Clin Res 2017;4:1-8.

25. Canayakin D, Bayir Y, Baygutalp NK, Karaoglan ES, Atmaca HT, Ozgeris FB, et al. Paracetamol-induced nephrotoxicity and oxidative stress in rats: The protective role of Nigella sativa. Pharm Biol 2016;54:2082-91.

26. Adil M, Kandhare AD, Ghosh P, Venkata S, Raygude KS, Bodhankar SL, et al. Ameliorative effect of naringin in acetaminophen-induced hepatic and renal toxicity in laboratory rats: Role of FXR and KIM-1. Ren Fail 
2016;38:1007-20.

27. Akindele AJ, Ezenwanebe KO, Anunobi CC, Adeyemi OO. Hepatoprotective and in vivo antioxidant effects of Byrsocarpus coccineus Schum and Thonn. (Connaraceae). J Ethnopharmacol 2010;129:46-52.

28. Singh A, Handa SS. Hepatoprotective activity of Apium graveolens and Hygrophila auriculata against paracetamol and thioacetamide intoxication in rats. J Ethnopharmacol 1995;49:119-26.

29. Parameshappa B, Basha MS, Sen S, Chakraborty R, Kumar GV, Sagar GV, et al. Acetaminophen-induced nephrotoxicity in rats: Protective role of Cardiospermum halicacabum. Pharm Biol 2012;50:247-53.
30. Adeneye AA, Benebo AS. Protective effect of the aqueous leaf and seed extract of Phyllanthus amarus on gentamicin and acetaminophen-induced nephrotoxic rats. J Ethnopharmacol 2008;118:318-23.

31. Ilbey YO, Ozbek E, Cekmen M, Somay A, Ozcan L, Otünctemur A, et al. Melatonin prevents acetaminopheninduced nephrotoxicity in rats. Int Urol Nephrol 2009;41:695-702.

32. Einas EM, Homeida MM, Adam SE. Effect of combined paracetamol and Cuminum cyminum and Nigella sativa use in wistar rats. J Pharmacol Toxicol 2007;2:653-9.

Source of Support: Nil. Conflict of Interest: None declared. 